\title{
Penerapan Matching pada Graf untuk Pendistribusian Pupuk Bersubsidi dengan Metode Hungarian
}

\author{
Eva Wahyu Listyawati ${ }^{1}$, Siti Amiroch ${ }^{2}$, Novita Eka Chandra ${ }^{3}$ \\ ${ }^{1}$ Universitas Islam Darul ‘ulum, evawahyulistyawati@gmail.com \\ ${ }^{2}$ Universitas Islam Darul ‘ulum Lamongan, siti.amiroch@unisda.ac.id \\ ${ }^{3}$ Universitas Islam Darul ‘ulum Lamongan, novitaeka@unisda.ac.id
}

\begin{abstract}
Increasing yields, demanding each farmer to improve the quality of agriculture, which in turn is expected to increase profits. The purpose of this paper is to determine the allocation of subsidized fertilizer distribution by the distributor of PT. Anak Gresik Raya Kencana and looking for the maximum number of subsidized fertilizer needs distributed in Lamongan district each year so that there is no scarcity and HET (Highest Retail Price) does not increase by applying the hungarian method. In this case, the problem is expressed as a bipartite graph, especially a complete weighted bipartite graph that applies the concept of matching, which is a perfect matching search with maximum weight using the Hungarian method. Matching is said to be perfect if it has fulfilled all the sets of vertices $X$ and $Y$. Obtained the results of the allocation of subsidized fertilizer distribution by the distributor of PT. Anak Gresik Raya Kencana is Deket sub-district requiring 1220 tons of SP-36, Glagah sub-district requires 3208 tons of Urea, Karangbinangun sub-district requires 483 tons of Organic, mantup sub-district requires 2079 tons of ZA, middle district needs 2233 tons of NPK and fertilizer distribution problems subsidized in Lamongan district can be completed with the maximum amount of subsidized fertilizer needs distributed as many as 9223 tons every year
\end{abstract}

Keywords: Matching on the Graph, Subsidized Fertilizer, Hungarian Method.

\begin{abstract}
Abstrak. Semakin meningkatnya hasil panen, menuntut setiap petani untuk meningkatkan kualitas pertaniannya yang pada akhirnya diharapkan dapat meningkatkan keuntungan. Tujuan penulisan ini untuk menentukan alokasi pendistribusian pupuk bersubsidi oleh distributor PT. Anak Gresik Raya Kencana dan mencari jumlah maksimum kebutuhan pupuk bersubsidi yang didistribusi di Kabupaten Lamongan tiap tahunnya sehingga tidak terjadi kelangkaan dan HET (Harga Eceran Tertinggi) tidak mengalami kenaikan dengan menerapkan metode hungarian. Dalam hal ini, permasalahan dinyatakan sebagai graf bipartit khususnya graf bipartit lengkap berbobot yang menerapkan konsep matching, yaitu pencarian perfect matching dengan bobot maksimum menggunakan metode Hungarian. Matching dikatakan sempurna jika telah memenuhi semua himpunan simpul $X$ dan $Y$. Diperoleh hasil alokasi pendistribusian pupuk bersubsidi oleh distributor PT. Anak Gresik Raya Kencana adalah kecamatan Deket membutuhkan SP-36 sebanyak 1220 ton, Kecamatan Glagah membutuhkan Urea sebanyak 3208 ton, Kecamatan Karangbinangun membutuhkan Organik sebanyak 483 ton, Kecamatan Mantup membutuhkan ZA sebanyak 2079 ton, Kecamatan Kalitengah membutuhkan NPK sebanyak 2233 ton dan masalah pendistribusian pupuk bersubsidi di Kabupaten Lamongan dapat diselesaikan dengan jumlah maksimum kebutuhan pupuk bersubsidi yang didistribusikan sebanyak 9223 ton tiap tahun.
\end{abstract}

Kata Kunci: Matching pada Graf, Pupuk Bersubsidi, Metode Hungarian. 


\section{Pendahuluan}

Kabupaten Lamongan merupakan kabupaten di wilayah Jawa Timur yang memiliki luas wilayah 181.280 Ha. Lahan di kabupaten ini didominasi oleh sektor pertanian dan mayoritas penduduk berprofesi sebagai petani. Sebanyak 12 kecamatan memiliki potensi pertanian terbesar di kabupaten Lamongan [1]. Lebih lanjut, [2] mengatakan sektor pertanian di kabupaten Lamongan perlu mendapat perhatian lebih guna meningkatkan nilai tukar petani yang cenderung menurun.

Selain itu, dalam sektor pertanian kabupaten Lamongan, pupuk merupakan salah satu unsur yang sangat berpengaruh terhadap hasil panen, khususnya pupuk bersubsidi. Pupuk bersubsidi didapatkan dari gudang penyedia pupuk yang ada di daerah tersebut. Di sisi lain, ketersediaan pupuk di gudang harus sesuai dengan jumlah kebutuhan petani agar tidak terjadi penimbunan atau kekurangan akan ketersediaan pupuk tersebut.

Untuk mengatasi hal tersebut diperlukan suatu metode hungarian dengan mencari perfect matching dengan bobot maksimal. Metode Hungarian adalah metode penugasan yang berkaitan dengan keinginan perusahaan dalam mendapatkan alokasi tugas yang optimal. Pada dasarnya pencarian perfect matching dengan bobot maksimal dapat dilakukan dengan mendaftar semua perfect matching yang berbeda dan menghitung jumlah bobot dari setiap perfect matching yang diperoleh.

Penelitian sebelumnya dilakukan oleh [3], menyimpulkan bahwa dengan menggunakan metode Hungarian terdapat efisiensi waktu dalam menyelesaikan masalah penugasan. Dalam hal penentuan matching, [4] mengatakan bahwa matching tersebut merupakan perfect matching dengan kardinalitas dan jumlah bobot sisi yang maksimum pada graf bipartit berbobot. Lebih lanjut, metode Hungarian dapat membantu perusahaan atau institusi dalam mengambil keputusan.

Pada penelitian ini akan dibahas metode hungarian untuk menyelesaikan matching pada graf bipartit lengkap berbobot dengan masalah yang akan dipecahkan adalah mencari solusi pendistribusian pupuk.

\section{Metode Penelitian}

Penelitian tentang penerapan metode Hungarian dalam penyelesaian matching pada graf untuk pendistribusian pupuk bersubsidi di Kabupaten Lamongan merupakan penelitian yang bersifat studi literatur dengan mempelajari materi yang berkaitan dengan buku, jurnal dan karya ilmiah lainnya. Penelitian ini dimulai dengan pengumpulan data dan data yang digunakan adalah data sekunder tentang laporan pendistribusian dan kebutuhan pupuk bersubsidi di Kabupaten Lamongan yang diperoleh dari Dinas Pertanian Kabupaten Lamongan. Tahap selanjutnya yaitu menentukan variabel $X$ (mewakili kecamatan di Kabupaten Lamongan) dan $Y$ (jenis pupuk bersubsidi). Dimana variabel $X$ terdiri dari $x_{1}$ adalah Kecamatan Deket; $x_{2}$ adalah Kecamatan Glagah; $x_{3}$ adalah Kecamatan Karangbinangun; $x_{4}$ adalah Kecamatan Mantup; dan $x_{5}$ adalah Kecamatan Kalitengah. Sedangkan variabel $Y$ terdiri dari $y_{1}$ adalah pupuk Urea; $y_{2}$ adalah pupuk SP-36; $y_{3}$ adalah pupuk ZA; $y_{4}$ adalah pupuk NPK; dan $y_{5}$ adalah pupuk Organik. Selanjutnya, membentuk matriks dari data pendistribusian pupuk tersebut dan tahap terakhir adalah melakukan perhitungan dengan metode Hungarian. 


\section{Hasil dan Pembahasan}

Penelitian tentang alokasi pendistribusian pupuk bersubsidi dapat dilakukan dengan menentukan variabel $X$ dan variabel $Y$ dari suatu data, membentuk sebuah matriks kemudian mengolah matriks tersebut dengan metode Hungarian. Berikut bentuk matriksnya sebagai berikut :

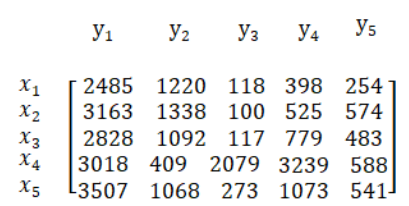

Setelah matriks terbentu, dilakukan pelabelan simpul $\ell$ dan dibentuk equality subgraph $G_{\ell}$. Diperoleh feasible labelling yang diilustrasikan pada matriks berikut:

\begin{tabular}{|c|c|c|c|c|c|c|}
\hline & $\mathrm{y}_{1}$ & $y_{2}$ & $y_{3}$ & $\mathrm{y}_{4}$ & $y_{5}$ & \\
\hline$x_{1}$ & 2485 & 1220 & 118 & 398 & 254 & 2485 \\
\hline$x_{2}$ & 3163 & 1338 & 100 & 525 & 574 & 3163 \\
\hline$x_{3}$ & 2828 & 1092 & 117 & 779 & 483 & 2828 \\
\hline$x_{4}$ & 3018 & 409 & 2079 & 3239 & 588 & 3239 \\
\hline \multirow[t]{2}{*}{$x_{5}$} & L 3507 & 1068 & 273 & 1073 & 541 & 3507 \\
\hline & 0 & 0 & 0 & 0 & 0 & \\
\hline
\end{tabular}

Sehingga diperoleh pelabelan simpul $\ell$ :

$$
\begin{aligned}
& \forall_{y} \in Y, \ell\left(y_{1}, y_{2}, y_{3}, y_{4}, y_{5}\right)=(0,0,0,0,0) \\
& \forall_{x} \in X, \ell\left(x_{1}, x_{2}, x_{3}, x_{4}, x_{5}\right)=(2485,3163,2828,3239,3507)
\end{aligned}
$$

dan digambarkan menjadi

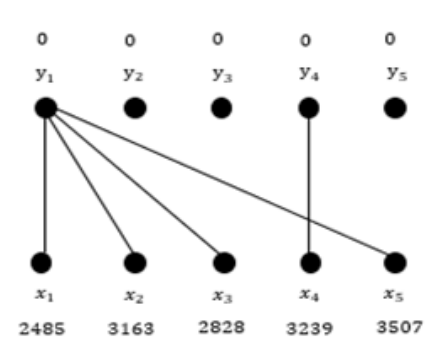

Gambar 1. Equality Subgraph $G_{\ell}$

Selanjutnya, dipilih sebarang matching $M$

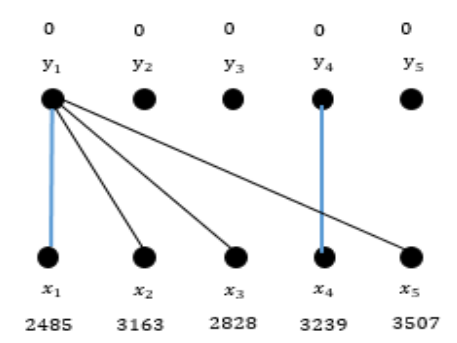

Gambar 2. Matching $M$

Matching $M$ pada Gambar 2 bukan matching sempurna, pilih sebarang $u \in X$ yang unsaturated di $M$. Didapatkan simpul $x_{2}, x_{3}, x_{5} \in X$, sehingga didefinisikan 
$S=\left\{x_{2}, x_{3}, x_{5}\right\}$ dan $T=\emptyset$. Simpul yang adjancent dengan simpul di $S$ adalah $y_{1}$, maka $N_{G_{\ell}}(S)=\left\{y_{1}\right\}$. Karena $N_{G_{\ell}}(S) \neq T$, maka pilih $y \in N_{G_{\ell}}(S)-T$. Diperoleh $y_{1}, y_{4} \in N_{G_{\ell}}(S)-T$, karena $y_{1}, y_{4}$ matched di matching $M$ dengan $x_{1}, x_{4} \in X$ dan $x_{1} y_{1}, x_{4} y_{4} \in M$, maka akan dibentuk lintasan $M$-alternating dengan menambahkan $S=\left\{x_{2}, x_{3}, x_{5}\right\} \cup\left\{x_{1}, x_{4}\right\}=\left\{x_{1}, x_{2}, x_{3}, x_{4}, x_{5}\right\} \quad$ dan $T=\emptyset \cup\left\{y_{1}, y_{4}\right\}=\left\{y_{1}, y_{4}\right\}$.

(a)

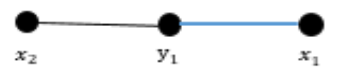

(b)

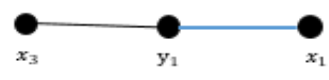

(c)

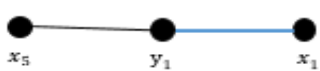

Gambar 3. (a) Lintasan M-alternating berawal dari simpul $x_{2}$; (b) Lintasan $M$ alternating berawal dari simpul $x_{3}$; (c) Lintasan M-alternating berawal dari simpul $x_{5}$

$S=\left\{x_{1}, x_{2}, x_{3}, x_{4}, x_{5}\right\} \quad$ dan $T=\left\{y_{1}, y_{4}\right\} \quad$ dan $N_{G_{\ell}}(S)=\left\{y_{1}, y_{4}\right\}$. Karena $N_{G_{\ell}}(S)=T$, maka hitung $\alpha_{\ell}$.

$$
\alpha_{\ell}=m_{x \in S, y \in T} \begin{cases}2485+0-1220=1265 & \left(x_{1}, y_{2}\right) \\ 2485+0-118=2367 & \left(x_{1}, y_{3}\right) \\ 2485+0-254=2231 & \left(x_{1}, y_{5}\right) \\ 3163+0-1338=1825 & \left(x_{2}, y_{2}\right) \\ 3163+0-100=3063 & \left(x_{2}, y_{3}\right) \\ 3163+0-574=2589 & \left(x_{2}, y_{5}\right) \\ 2828+0-1092=1736 & \left(x_{3}, y_{2}\right) \\ 2828+0-117=2711 & \left(x_{3}, y_{3}\right) \\ 2828+0-483=2345 & \left(x_{3}, y_{5}\right) \\ 3239+0-409=2830 & \left(x_{4}, y_{2}\right) \\ 3239+0-2079=1160 & \left(x_{4}, y_{3}\right) \\ 3239+0-588=2651 & \left(x_{4}, y_{5}\right) \\ 3507+0-1068=2439 & \left(x_{5}, y_{2}\right) \\ 3507+0-273=3234 & \left(x_{5}, y_{3}\right) \\ 3507+0-541=2966 & \left(x_{5}, y_{5}\right)\end{cases}
$$

Diperoleh $\alpha_{\ell}=1160$ pada $\left(x_{4}, y_{3}\right)$. Kurangi elemen pada label $S=\left\{x_{1}, x_{2}, x_{3}, x_{4}, x_{5}\right\}$ dengan 1160 dan tambahkan elemen-elemen label $T=\left\{y_{1}, y_{4}\right\}$ dengan 1160 .

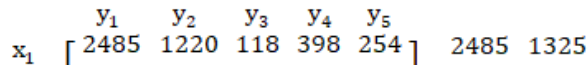

$$
\begin{aligned}
& \mathrm{x}_{1} \quad\left[\begin{array}{lllll}
2485 & 1220 & 118 & 398 & 254 \\
3163 & 1338 & 100 & 525 & 574 \\
2828 & 1092 & 117 & 779 & 483
\end{array}\right] \begin{array}{ll}
2485 & 1325 \\
3163 & 2003
\end{array} \\
& \begin{array}{l|llllll|ll}
\mathrm{x}_{2} & 2828 & 1092 & 117 & 779 & 483 & 2828 & 1668
\end{array} \\
& \begin{array}{lllllll|ll}
\mathrm{x}_{3} & 3018 & 409 & 2079 & 3239 & 588 & 3239 & 2079
\end{array} \\
& \mathrm{x}_{4} \quad\left[\begin{array}{lllll}
3507 & 1068 & 273 & 1073 & 541
\end{array}\right] \quad \begin{array}{llll}
3507 & 2347
\end{array} \\
& \mathrm{x}_{5} \\
& \begin{array}{ccccc}
0 & 0 & 0 & 0 & 0 \\
1160 & 0 & 0 & 1160 & 0
\end{array}
\end{aligned}
$$

Diperoleh pelabelan simpul $\ell^{\prime}$ :

$$
\begin{aligned}
& \forall y \in Y, \ell^{\prime}\left(y_{1}, y_{2}, y_{3}, y_{4}, y_{5}\right)=(1160,0,0,1160,0) \\
& \forall y \in X, \ell^{\prime}\left(x_{1}, x_{2}, x_{3}, x_{4}, x_{5}\right)=(1325,2003,1668,2079,2347)
\end{aligned}
$$




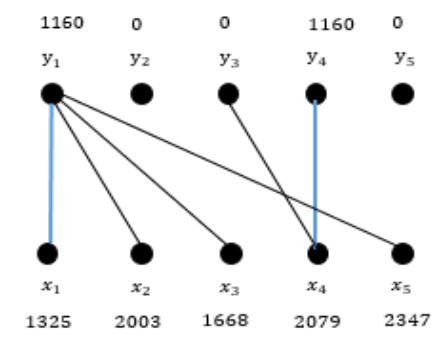

Gambar 4. Equality Subgraph $G_{\ell}{ }^{\prime}$ dan Matching $M$

$S=\left\{x_{1}, x_{2}, x_{3}, x_{4}, x_{5}\right\} \quad, \quad T=\left\{y_{1}, y_{4}\right\} \quad$ dan $N_{G_{\ell}}(S)=\left\{y_{1}, y_{3}, y_{4}\right\} \quad$.Karena $N_{G_{\ell}}(S) \neq T$, maka pilih $y \in N_{G_{\ell}}(S)-T . y_{3} \in N_{G_{\ell}{ }^{\prime}}(S)-T$, karena $y_{3}$ unmatched di matching $M$, maka terdapat $P$ yang merupakan lintasan $M$ augmenting $u-y$, yaitu : $P_{1}=\left\{\left(x_{4}, y_{4}\right),\left(x_{4}, y_{3}\right)\right\}$

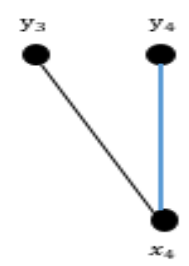

Gambar 5. Lintasan M-augmenting $P_{1}$

Selanjutnya, mengubah $M$ dengan $M^{\prime}$, sehingga

$$
\begin{aligned}
& M^{\prime}=M \Delta P_{1} \\
& M^{\prime}=\left\{\left(x_{1}, y_{1}\right),\left(x_{4}, y_{4}\right)\right\} \Delta\left\{\left(x_{4}, y_{4}\right),\left(x_{4}, y_{3}\right)\right\} \\
& M^{\prime}=\left\{\left(x_{1}, y_{1}\right),\left(x_{4}, y_{3}\right)\right\}
\end{aligned}
$$

Matching $M^{\prime}$ bukan matching sempurna, maka pilih sebarang $u \in X$ yang unsaturated di $M^{\prime}$. Diperoleh simpul $x_{2}, x_{3}$ dan $x_{5} \in X$ sehingga didefinisikan $S=\left\{x_{2}, x_{3}, x_{5}\right\}$ dan $T=\emptyset$.

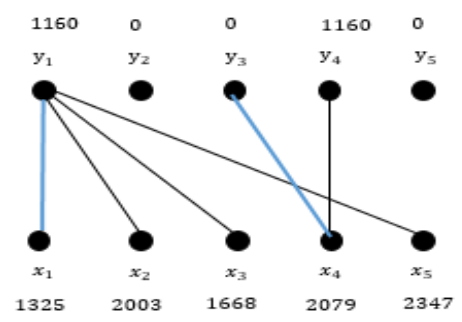

Gambar 6. Equality Subgraph $G_{\ell}{ }^{\prime}$ dan Matching $M^{\prime}$

$S=\left\{x_{2}, x_{3}, x_{5}\right\}, T=\emptyset$ dan $N_{G_{\ell}}(S)=\left\{y_{1}\right\}$. Karena $N_{G_{\ell}}(S) \neq T$, maka pilih $y \in N_{G_{\ell}}(S)-T$. Diperoleh $y_{1} \in N_{G_{\ell}}(S)-T$, karena $y_{1}$ matched di matching $M^{\prime}$, maka bentuk lintasan M-alternating dengan menambahkan $S=\left\{x_{2}, x_{3}, x_{5}\right\} \cup\left\{x_{1}\right\}=\left\{x_{1}, x_{2}, x_{3}, x_{5}\right\}$ dan $T=\emptyset \cup\left\{y_{1}\right\}=\left\{y_{1}\right\}$. Lintasan $M$ alternating yang dibentuk sama dengan Lintasan M-alternating pada Gambar 3 . 
$S=\left\{x_{1}, x_{2}, x_{3}, x_{5}\right\}, T=\left\{y_{1}\right\}$ dan $N_{G_{\ell}}(S)=\left\{y_{1}\right\}$. Karena $N_{G_{\ell}}(S)=T$, maka hitung $\alpha_{\ell}$.

$$
\alpha_{\ell}=m_{x \in S, y \in T}\left(\begin{array}{cc}
1325+0-1220=105 & \left(x_{1}, y_{2}\right) \\
1325+0-118=1207 & \left(x_{1}, y_{3}\right) \\
1325+1160-398=2087 & \left(x_{1}, y_{4}\right) \\
1325+0-254=1071 & \left(x_{1}, y_{5}\right) \\
2003+0-1338=665 & \left(x_{2}, y_{2}\right) \\
2003+0-100=1903 & \left(x_{2}, y_{3}\right) \\
2003+1160-525=2638 & \left(x_{2}, y_{4}\right) \\
2003+0-574=1429 & \left(x_{2}, y_{5}\right) \\
1668+0-1092=576 & \left(x_{3}, y_{2}\right) \\
1686+0-117=151 & \left(x_{3}, y_{3}\right) \\
1668+1160-779=2049 & \left(x_{3}, y_{4}\right) \\
1668+0-483=1185 & \left(x_{3}, y_{5}\right) \\
2347+0-1068=1279 & \left(x_{5}, y_{2}\right) \\
2347+0-273=2074 & \left(x_{5}, y_{3}\right) \\
2347+1160-1073=2434 & \left(x_{5}, y_{4}\right) \\
2347+0-541=1806 & \left(x_{5}, y_{5}\right)
\end{array}\right.
$$

Diperoleh $\alpha_{\ell}=105$ pada $\left(x_{1}, y_{2}\right)$

$$
\begin{aligned}
& \begin{array}{lllll}
y_{1} & y_{2} & y_{3} & y_{4} & y_{5}
\end{array} \\
& \mathrm{x}_{1}\left[\begin{array}{llllll}
2485 & 1220 & 118 & 398 & 254 \\
3163 & 1338 & 100 & 525 & 574
\end{array}\right] \begin{array}{llll}
2485 & 1325 & 1220
\end{array} \\
& \begin{array}{lllll|lll}
3163 & 1338 & 100 & 525 & 574 & 3163 & 2003 & 1898
\end{array} \\
& \begin{array}{llllll|lll}
2828 & 1092 & 117 & 779 & 483 & 2828 & 1668 & 1563
\end{array} \\
& \begin{array}{cccccc|ccc}
2828 & 1092 & 117 & 779 & 483 & 2828 & 1668 & 1563 \\
3018 & 409 & 2079 & 3239 & 588 & 3239 & 2079 & 2079
\end{array} \\
& \mathrm{x}_{4} \quad\left[\begin{array}{llllllll}
3507 & 1068 & 273 & 1073 & 541
\end{array}\right] \begin{array}{lllll}
3507 & 2347 & 2242
\end{array} \\
& \mathrm{x}_{5} \\
& \begin{array}{ccccc}
0 & 0 & 0 & 0 & 0 \\
1160 & 0 & 0 & 1160 & 0
\end{array} \\
& \begin{array}{lllll}
1310 & 0 & 0 & 1160 & 0
\end{array}
\end{aligned}
$$

Pelabelan simpul baru $\ell^{\prime \prime}$ :

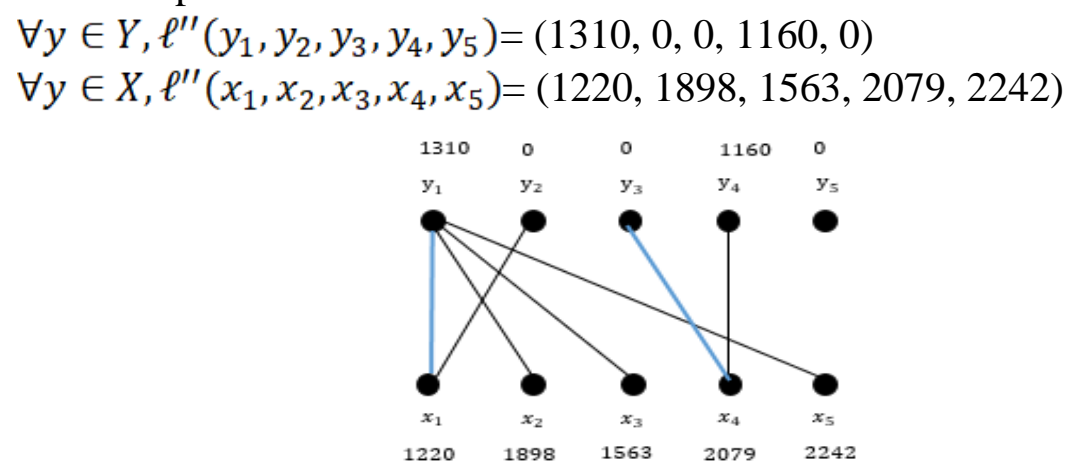

Gambar 7. Equality Subgraph $G_{\ell}{ }^{\prime \prime}$ dan Matching $M^{\prime}$

$S=\left\{x_{1}, x_{2}, x_{3}, x_{5}\right\}, T=\left\{y_{1}\right\}$ dan $N_{G_{\ell}}(S)=\left\{y_{1}, y_{2}\right\}$. Karena $N_{G_{\ell}}(S) \neq T$, maka pilih $y \in N_{G_{\ell}}{ }^{\prime \prime}(S)-T . y_{1}, y_{2} \in N_{G_{\ell}}{ }^{\prime \prime}(S)-T$. Karena $y_{2}$ unmatched pada matching $M^{\prime}$, maka bentuk lintasan M-augmenting $u-y$, yaitu : $P_{2}=\left\{\left(x_{1}, y_{2}\right),\left(x_{1}, y_{1}\right),\left(x_{2}, y_{1}\right)\right\}$.

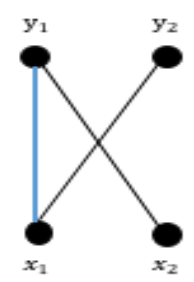

Gambar 8. Lintasan M-augmenting $P_{2}$ 
Ganti $M^{\prime}$ dengan $M^{\prime \prime}$,

$M^{\prime \prime}=M^{\prime} \Delta P_{2}$

$M^{\prime \prime}=\left\{\left(x_{1}, y_{1}\right),\left(x_{4}, y_{3}\right)\right\} \Delta\left\{\left(x_{1}, y_{2}\right),\left(x_{1}, y_{1}\right),\left(x_{2}, y_{1}\right)\right\}$

$M^{\prime \prime}=\left\{\left(x_{1}, y_{2}\right),\left(x_{2}, y_{1}\right),\left(x_{4}, y_{3}\right)\right\}$

Matching $M^{\prime \prime}$ bukan matching sempurna

Ulangi langkah di atas hingga 26 langkah sampai diperoleh matching sempurna, yaitu :

$$
M=\left\{\left(x_{1}, y_{2}\right),\left(x_{2}, y_{1}\right),\left(x_{3}, y_{5}\right),\left(x_{4}, y_{3}\right),\left(x_{5}, y_{4}\right)\right\}
$$

Dengan begitu, diperoleh nilai solusi optimal dengan menjumlahkan semua nilai feasible labelling pada equality subgraph $G_{\ell}$, yaitu :

$611+729+483+2079+1073+0+1160+0+609+2479=9223$

Jadi pendistribusian pupuk bersubsidi pada 5 kecamatan di Lamongan sebagai berikut :

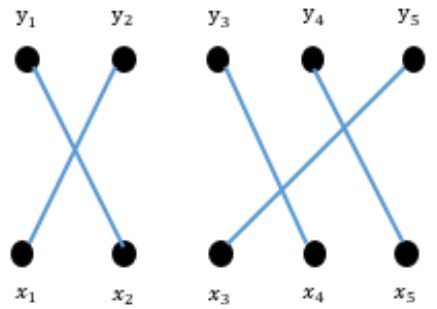

Gambar 9. Matching sebagai solusi masalah pendistribusian pupuk bersubsidi

Berdasarkan hasil matching pada Gambar 9, maka alokasi pendistribusian pupuk bersubsidi yang sebaiknya dilakukan oleh distributor PT. Anak Gresik Raya Kencana adalah:

a. Kecamatan Deket $\left(x_{1}\right)$ membutuhkan pupuk bersubsidi SP-36 $\left(y_{2}\right)$ dengan jumlah pupuk yang dibutuhkan sebanyak 1220 ton.

b. Kecamatan Glagah $\left(x_{2}\right)$ membutuhkan pupuk bersubsidi Urea $\left(y_{1}\right)$ dengan jumlah pupuk yang dibutuhkan sebanyak 3208 ton.

c. Kecamatan Karangbinangun $\left(x_{3}\right)$ membutuhkan pupuk bersubsidi Organik $\left(y_{5}\right)$ dengan jumlah pupuk yang dibutuhkan sebanyak 483 ton.

d. Kecamatan Mantup $\left(x_{4}\right)$ membutuhkan pupuk bersubsidi ZA $\left(y_{3}\right)$ dengan jumlah pupuk yang dibutuhkan sebanyak 2079 ton.

e. Kecamatan Kalitengah $\left(x_{5}\right)$ membutuhkan pupuk bersubsidi NPK $\left(y_{4}\right)$ dengan jumlah pupuk yang dibutuhkan sebanyak 2233 ton.

\section{Kesimpulan}

Dari hasil dan pembahasan yang dilakukan, disimpulkan bahwa dengan metode Hungarian, masalah pendistribusian pupuk bersubsidi di Kabupaten Lamongan dapat diselesaikan dengan jumlah maksimum kebutuhan pupuk bersubsidi yang didistribusikan sebanyak 9223 ton tiap tahun.

\section{Daftar Pustaka}

[1] A. Rohmatullah, D. Rahmalia, and M. S. Pradana, "Klasterisasi Data Pertanian di Kabupaten Lamongan Menggunakan Algoritma K-Means Dan 
Fuzzy C Means," J. Ilm. Teknosains, vol. 5, no. 2, pp. 86-93, 2019.

[2] M. S. Pradana, D. Rahmalia, and E. D. A. Prahastini, "Peramalan Nilai Tukar Petani Kabupaten Lamongan dengan Arima," J. Mat., vol. 10, no. 2, pp. 91-104, 2020.

[3] D. Harini, "Optimasi Penugasan Menggunakan Metode Hungarian," INTENSIF J. Ilm. Penelit. dan Penerapan Teknol. Sist. Inf., vol. 1, no. 2, pp. 68-74, 2017.

[4] M. Abrori and R. Wahyuningsih, "Penentuan Matching Maksimum Pada Graf Bipartit Berbobot Menggunakan Metode Hungarian," J. Ilm. Tek. Ind., vol. 11, no. 1, pp. 9-21, 2012. 